\title{
Dos siglos de anticlericalismo en Francia: historia y representación literaria*
}

\author{
José María FERNÁNDEZ CARDO \\ Universidad de Oviedo \\ cardo@uniovi.es \\ http://orcid.org/0000-0003-2566-0040
}

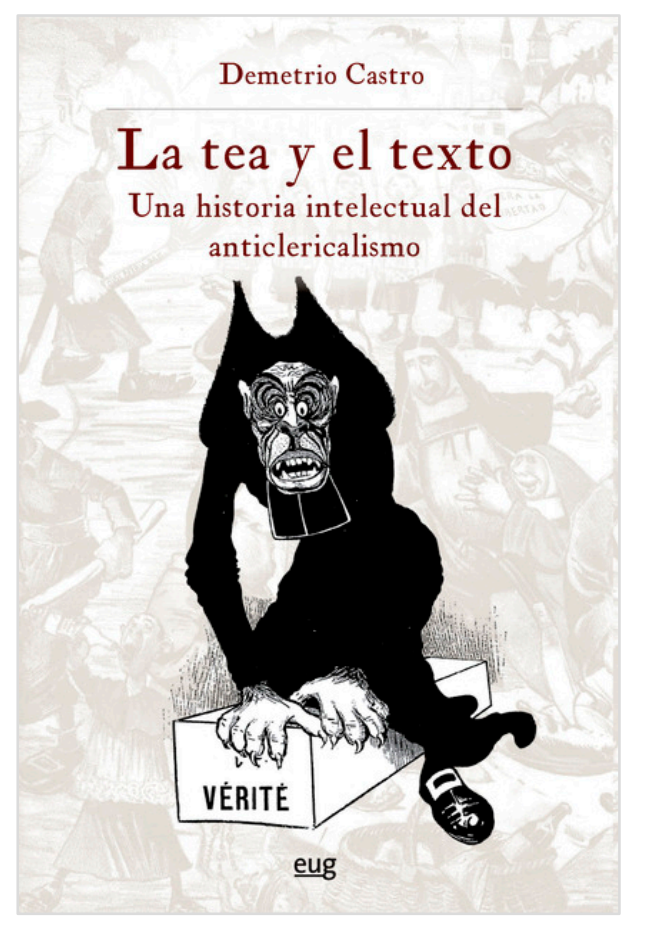

Con un título tan sugerente como el de La tea y el texto, Demetrio Castro ha escrito un volumen de cerca de quinientas páginas sobre un asunto que, en mi opinión, desde el ámbito de los estudios franceses, es bienvenido, puede arrojar mucha luz sobre aspectos importantes de la sociedad representada en la literatura de los siglos XVIII y XIX. Bastaría con desplegar en toda su amplitud una noción como la de intertexto, dentro de la que el discurso histórico está llamado a ocupar un espacio de privilegio, si no determinante, junto a los otros lenguajes discursivos. Y a ello incita, ciertamente, la palabra texto, colocada junto a la de tea que enciende el emblema titular, iluminándolo.

Sabíamos que durante el período revolucionario en Francia, y en particular durante la última década del siglo, a partir de 1790, los vientos no habían soplado a favor de los eclesiásticos, seculares o miembros de órdenes religiosas; sabíamos también que las relaciones de la de San Ignacio, los jesuitas, con los estados meridionales europeos habían conocido períodos tormentosos, que motivaron la consiguiente sarta de expulsiones recogidas en los libros de historia, y sabíamos igualmente que, desde el jansenismo

* Acerca del libro de Demetrio Castro, La tea y el texto. Una historia intelectual del anticlericalismo (Granada, Editorial Universidad de Granada, colección «Historia», 2020, 492 p. ISBN: 978-84-338-6640$0)$. 
y Port-Royal, por mucho que Luis XIV hubiera puesto su empeño en borrar del mapa las huellas de la abadía fundacional, subsistieron la represión y el conflicto con las ideas religiosas dentro del estado absoluto.

Largo y sinuoso, sin duda, fue el camino recorrido en Francia durante el Siglo de las Luces en la dirección de reivindicar la separación de las cosas de Dios y las de los hombres, a través de las críticas de los filósofos a la teología y a la superstición religiosa desde los postulados que reivindicaban la razón. Como tampoco fue de rosas el camino de liberales y republicanos franceses durante la centuria siguiente, dentro de la particular historia del Hexágono en el siglo XIX, pendular donde las haya: del Imperio a la Restauración borbónica, de la monarquía del Rey Ciudadano a la República, de la II República al otro Imperio y después a la IIIa, hasta que a lo largo del siglo XX la laicidad del estado llega a erigirse en uno de los pilares republicanos mejor asentados. Hasta aquí el diccionario de las «ideas recibidas», por recuperar una expresión de sesgo flaubertiano...

Cabe ahora preguntarse dónde se sitúa el libro de Demetrio Castro y cuál es su perspectiva. La primera tentación de superficie, basada en la simple apreciación de la masa textual, consistiría en decir que su recorrido es lisa y llanamente enciclopédico, a poco que el lector proceda a realizar el recuento de la bibliografía citada -en torno a seiscientos títulos, con ligero riesgo de equivocación a la baja- y un millar de notas novecientas noventa y ocho por mor de exactitud-, lo que no es óbice para impedir la placentera lectura de un texto principal que campa por sus fueros, bien asentado documentalmente en las referencias precisas a pie de página. El libro, tal como señala el autor en la Introducción, es un trabajo de muchos años, fruto de discusiones académicas con colegas y de numerosas estancias en bibliotecas extranjeras de ensueño para los estudiosos (Harvard, Cambridge).

El propósito primero del libro es el de «indagar cómo se ha expresado, en tanto que fenómeno social e intelectual, el anticlericalismo en la historia de Europa» (p. 11), tal como el subtítulo se encarga de matizar, Una historia intelectual del anticlericalismo. A medida que el lector avanza va descubriendo que la indagación se remonta hasta las fuentes de la Europa medieval, pasa por las corrientes de la Reforma renacentista y las guerras de religión, para desembocar a partir del siglo XVIII sobre todo en Francia y en España, además de prestar oído atento a lo que ocurre en la geografía italiana en la que se asientan los dominios vaticanos. Se detiene su estudio en los albores del siglo $\mathrm{XX}$, a sabiendas de que, por ejemplo, el caso espańol (en las inmediaciones, durante y después de la Guerra Civil) merecería una consideración de carácter monográfico. La tea y el texto proporciona un marco conceptual e histórico, en el que cabría fundamentar el estudio sobre las manifestaciones españolas del anticlericalismo en el siglo XX.

Sorprende al lector la estrategia de análisis adoptada por el autor de La tea y el texto para las manifestaciones del anticlericalismo en los siglos medievales, al agrupar el resultado de su investigación bajo epígrafes latinos que, de algún modo, recuerdan la 
tópica taxonómica de aquel tiempo: AVARITIA, INCURIA-NeSCIENTIA, LUXURIA, FUROR-EXCIDIUM. Presta atención especial a los avatares del concubinato de los clérigos durante la Edad Media y comienzos de la Moderna, del que dan cuenta muchos textos canónicos, disciplinarios, documentales y también literarios. Demetrio Castro revisa tal cantidad de documentación en estos apartados que el resultado colmará, sin duda, las expectativas de los medievalistas interesados (historiadores de la Historia y de la Literatura), considerando además que huye de la tentación del "presentismo», ya que el pasado no puede interpretarse desde los valores del presente (p. 21)

Las manifestaciones del anticlericalismo durante el Siglo de la Ilustración ocupan un denso capítulo de cincuenta páginas, que no se deja resumir, hay que leerlo. Me conformaré con traer aquí los títulos de los apartados de que consta: «Intelectuales, opinión y querellas en la Francia del siglo XVIII», "Literatura anticlerical. Temas. Tipos. Recursos», "Discurso y acción colectiva anticlerical: el lugar de la propaganda del siglo XVIII», "También en España». Sucede aquí como en otros capítulos, en varios casos a modo de coda, que el autor presta atención particular al mismo fenómeno, pero en "versión espańola», por así decir, considerando que con matices diversos las manifestaciones anticlericales ocurren en los dos países de forma paralela, con alguna distancia cronológica, explicable por la colonización cultural ejercida, durante aquella centuria, sobre nuestro país por los vecinos del Norte. Y no cabe duda de que la incorporación de la perspectiva comparada confiere al libro un valor añadido, además de poner de manifiesto que la escritura de una historia cultural europea es posible.

En el capítulo siguiente, el tercero, «Tiempos nuevos mientras siguen los viejos. Anticlericalismo y Revolución Francesa», el lector accede a un detallada exposición de la política religiosa durante aquellos tiempos convulsos, política que cada vez se mostraba más anticlerical y generaba un movimiento de suspicacia con relación a los eclesiásticos y la adhesión de éstos a la Revolución: «En algunos lugares, se les acosaba para que lucieran la escarapela tricolor o manifestasen su apoyo a la nacionalización de los bienes de la Iglesia, o a que se sumasen a la celebración de festividades políticas, forzándoles a hacerlo en ocasiones de manera que, por lo estrafalario, no dejaba de encerrar deliberado propósito de ultraje al modo de entender, según los criterios vigentes, su dignidad» (p. 133).

En razón del interés que suscitan todos y cada uno de los capítulos, en total ocho, la primera tentación de quien escribe estas líneas sería la de ofrecer el resumen de todos, pero ha debido autoimponerse la disciplina de resistirse a ella para reservar un poco de espacio a la mención, al menos, de un texto representativo dentro de la historia literaria del siglo XIX francés, que Demetrio Castro analiza como ejemplo señero de la representación del anticlericalismo: Le juif errant de Eugène Sue, cuyo estudio adquiere un gran protagonismo en el capítulo sexto, «Clericalismo de ficción». Fue esta una de las novelas más populares en la Francia de aquel siglo, que comenzó a publicarse en 1844 por entregas, en forma de folletín, coincidiendo con las conferencias 
que por la misma época pronunciaban en el Colegio de Francia Michelet y Quinet contra la orden de San Ignacio. El título de la novela podría resultar un poco engañoso porque de lo que trata en realidad es de un descendiente de protestantes que los jesuitas habían forzado al suicidio, en su afán de hacerse con una herencia fabulosa. Publicada en una época en que se debatía en Francia sobre la enseñanza secundaria, lo que vino a suscitar fue un verdadero movimiento de «jesuitofobia». Eugène Sue, en el epílogo de la misma, «sostiene, exhumando las acusaciones jansenistas, que los teólogos jesuitas exculpan el robo, el adulterio, la violación o el asesinato, y que él se ha limitado a poner en acción sus doctrinas detestables» (p. 265). Demetrio Castro señala que el escritor se hace presente en todo momento en el texto de la novela, poniendo ejemplos en las notas sobre la veracidad de los elementos narrados en la ficción, llegando incluso a detallar las posesiones de la Compañía durante el período de la Restauración, lo que no dejará de conferirle un valor histórico y documental, rayano en ocasiones con los mensajes propios de la escritura panfletaria (pp. 266-267). La novela, cuyas primeras entregas vieron la luz en Francia, bajo los auspicios del periódico Le Constitutionnel, en junio de 1844, comenzaría muy rápidamente a difundirse en español: al mes siguiente, en julio, en El Heraldo se empieza a publicar la traducción de la novela.

No se limita el autor de La tea y el texto a los grandes autores emblemáticos de la historia literaria de Francia (Stendhal, Balzac o Zola), sino que su discurso histórico sobre el anticlericalismo escudrińa publicaciones poco conocidas, algunas de ellas periódicas, en las que fundamenta parte de su trabajo investigador; de ahí la sensación de sorpresa del lector interesado a medida que atraviesa el bosque de los párrafos y los capítulos. Las publicaciones periódicas de carácter satírico le han permitido extraer un material de primera mano como refrendo de una argumentación que, en ocasiones, se tiñe con el humor negro a través del que se expresa la ideología de forma contundente, sin ambages, ni rodeos (iluminaciones). A este fin sirve precisamente el ULTÍLOGO GRÁFICO -forma de apéndice textual, después de la bibliografía-, que da cuenta de la serie de cuarenta y cinco ilustraciones visuales del anticlericalismo, la última de ellas de 1910, la portada de El motín, del jueves 27 de enero, en la que se representa a un obispo, de panza prominente y espada en ristre, predicando el exterminio de los liberales de hoy, sobre los cráneos de los de ayer.

Es en las primeras páginas del «Ultílogo» donde el lector, que no hubiera prestado atención suficiente a la solapa interior de la portada (Imágenes de cubierta), dará por fin satisfacción a la curiosidad que le venía embargando desde su primer contacto con el libro: una vińeta de la revista La Calotte (abril de 1907), que es la que se reproduce en la cubierta, representa a un cura de aspecto ferino sepultando la verdad, acompañada de la leyenda "pese a tu engańo, tu astucia y todos los vicios en que te cebas, la Verdad saldrá de la tumba y te aterrorizará, cuervo vil». Por simple asociación de palabras y de ideas, y ya que Émile Zola fue mencionado en el párrafo precedente, no estará de más traer aquí a colación, de manera breve, la novela de este autor, publicada en los 
albores del siglo XX que lleva el título de Vérité, porque de ella también se ocupa in extenso Demetrio Castro como novela de la crónica del anticlericalismo. En efecto, en ella el novelista se hacía eco de un caso muy comentado en la Francia de 1899, el del hermano de las Escuelas Cristianas Flamidien, «a quien se procesó, encarceló y convirtió en centro de una apasionada polémica pública entre quienes sostenían su culpabilidad y hacían del suceso argumento para la eliminación absoluta de la enseńanza confesional» (pp. 385-386). Una especie de caso Dreyfus en versión religiosa, porque la opinión pública francesa al respecto se partió en dos.

Por último, y referida también a aquella época tan convulsa ideológicamente para el país vecino, de finales del siglo XIX y principios del XX, no debe quedar en el tintero la evocación de un asunto al que el autor de La tea y el texto dedica una especial atención en el último capítulo: el de "las fichas del general André», escándalo de espionaje corrupto donde los haya y del que quizás no se ha tenido por estos pagos hispánicos el conocimiento y la información requeridos por el caso. El mencionado general, al frente del Ministerio del Ejército, a partir de 1900, puso en marcha un sistema de fichas que informaban sobre el comportamiento religioso de los militares de profesión, capaz de influir en la promoción de ascenso: en ellas figuraba, junto a otras anotaciones, si iban o no a misa los domingos, como signo de fidelidad o infidelidad republicanas... El recorrido de este apartado del capítulo octavo colmará no sólo las expectativas del lector deseoso de conocer la verdad histórica del suceso, sino que vendrá a satisfacer, por el insólito carácter de lo narrado, su curiosidad novelística.

Este ensayo de Demetrio Castro sobre la historia intelectual del anticlericalismo viene a poner de relieve que para escribir la Historia debe contarse también con los escritos ardientes de la literatura coetánea, que no suelen ser objeto de excesiva consideración, o por lo menos en la dimensión que merecen, para los historiadores de profesión. Y viceversa, A La tea y el texto le sobra fuelle para avivar el fuego de muchos estudios literarios que están por venir y que encontrarán en este libro la perspectiva conceptual y la documentación histórica necesarias para otorgarles una dimensión intertextual, entendida como polifonía auténtica de los discursos. 